\section{Journals and databanks}

SIR-Recent discussions in these pages ("Who's hiding the primary data?" Nature 341, 94; 1989 and "Making good databanks better" 341, 277; 1989) have praised the goals of the biological databases, pointed out some problems with them, but rejected a role for journals in ensuring their completeness. While we welcome your enthusiasm for our goals, the arguments against the role for journals fail to take account of the facts.

Insistence on deposition of data is seen by you as an unreasonable burden on authors: journals should not be watchdogs; there should be as few obstacles between the author and publication as possible; political, economic and technical restrictions render access to the databases patchy, and it is unreasonable to insist that scientists contribute to a resource that serves them only poorly. Arguments about the workability (there are so many databases nowadays) and enforceability of deposition schemes are also raised.

That journals are watchdogs is already a fact - non-trivial publication standards and review procedures are already in place to ensure the scientific integrity of what they publish. That these procedures are an obstacle between the author and publication does not, of course, justify the creation of others, but the deposition of sequence data is a necessary part of ensuring integrity. It is now common for articles to discuss sequences or structures not actually presented, and even presented sequences would be more accessible in a computer database. Readers cannot assess conclusions based on data they cannot see. Your leading article "Making good databanks better" even stresses that journals should ask for and make available such supporting data as are appro-

\section{MS processing}

SIR-Nature has done a service to authors in an earlier issue this year by publishing the median times in which it accomplishes each stage of manuscript processing. I hope that other journals will take up the same practice. What would be desirable is that all journals not only report on this matter periodically as Nature proposes to do, but also reprint the essential statistics at last compilation on the same page or pages where they give their instructions to authors, page charges, reprint prices and so on. A would-be author could then easily find the information when he especially needs it: that is, when considering the advantages and disadvantages of submitting to a particular journal.

RICHARD F. SHAW 10201 Grosvenor Place, Apt 522, North Bethesda, Maryland 20852, USA priate. What better way is there to do that than through the centralized databases?

That access to the databases is uneven is true. Any implication that we complacently direct our efforts to the service of a high-tech subcommunity is not. For some less well equipped users, we produce tape formats long-since obsolete. Our CD-ROM is targeted for users in lowinvestment computer environments. It also contains search software that may help to obviate the need to purchase expensive third-party products.

Nonetheless, inequalities exist: but nor are journals, libraries and scientific equipment equally accessible to all. The decision not to include the Soviet Union in the present tripartite nucleotide sequence database collaboration was based purely on a notion of diminishing returns with increasing numbers of collaborators. We routinely exchange data with them.

The databases, again like journals, libraries and scientific equipment, are as accessible to commercial organizations as to academic researchers. Publication of scientific findings (in databases or journals) renders them available for exploration. For the sequence database, this is no bad thing. The development of software tools for exploring genome data is in its infancy. Maintaining the complete data collections in the public domain allows any group commercial or academic - to carry out research in this area and promotes a diversity of approaches appropriate at this stage.

The workability and enforceability of our data deposition systems is no longer a matter of debate, a number of journals already operate such systems with total compliance, and our feedback from editors and authors is positive. Also, some attempt to minimize the problems of dealing with multiple databanks is being made. The United States, Japan and Europe all have nucleotide and protein sequence databases (incidentally the DNA Database of Japan is at the National Institute of Genetics in Mishima, not the Riken Laboratory as you suggest). These six sequence databases have agreed to deal with journals in a coordinated manner.

Insofar as the databases are pleading for data, they are reflecting the demands of the scientific community. It is the users publishing scientists themselves - who need the data. We do all in our power to ensure the completeness of our collections, but the task is enormous. Without the support of the researchers at large, we will serve them poorly. For unpublished, possibly confidential data, deposition can be urged. For published data, our goals are compatible with those of the journals. Network access to our databases has been possible since June 1988; it is not, as you suggest, a thing of the future. Readers of journals enforcing deposition can typically access the data on the day they receive the journal. The two information resources work well together.

On receipt of reasonably documented nucleotide sequence submissions, we issue accession numbers within one week. They are proof of deposition and an unchanging pointer to the data. We feel it would be appropriate for Nature to insist that such numbers be presented at some time in the publication process.

GRAHAM CAMERON PATRICIA KAHN LENNART PHILIPSON

European Molecular Biology Laboratory, Postfach 10.2209,

6900 Heidelberg, FRG

\section{How not to defeat terrorism}

SIR-Robert Michaels' suggestion (Nature 342, 336; 1989) that the problem of terrorist bombings of airplanes might be solved by the exclusion of oxygen from the cargo holds of aircraft is ingenious but I am afraid it will not work. Modern molecular explosives, such as TNT, PETN and RDX, do not require oxygen for their detonation but instead contain both oxidant and fuel within the same molecule. For example, the military explosive RDX decomposes on detonation according to the following scheme:

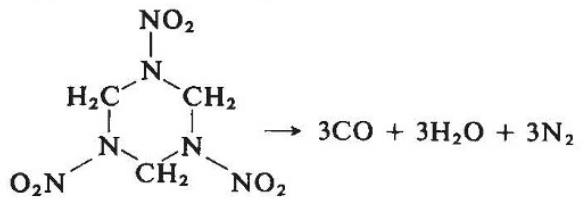

Department of Chemistry,

University of Warwick,

Coventry CV4 7AL, UK

SIR-Robert A. Michaels (Nature 342, $336 ; 1989)$ proposes to suffocate terrorist bombs by flushing aircraft luggage bins with nitrogen. DREADCO's torpedo experts assure me that explosives are immune from suffocation. They can explode quite happily in nitrogen, or indeed under water. Human beings, however, are not so self-contained. Michaels' system would merely expose the hapless passengers to a new risk - that of suffocation from nitrogen-leaks. On the bright side, however, it would certainly discourage smokers.

DAEDALUS

University of Newcast/e upon Tyne, UK

Letters submitted for Correspondence should be typed, double-spaced, on one side of the paper only. 